\title{
Reduction in black carbon light absorption due to multi-pollutant emission control during APEC China 2014
}

\author{
Yuxuan Zhang ${ }^{1,2}$, Xin Li ${ }^{1}$, Meng Li ${ }^{1,2}$, Yixuan Zheng ${ }^{1}$, Guannan Geng ${ }^{1}$, Chaopeng Hong ${ }^{1}$, Haiyan Li $^{3}$, Dan Tong ${ }^{1}$, \\ Xin Zhang ${ }^{1}$, Yafang Cheng ${ }^{4,2}$, Hang Su${ }^{4,2}$, Kebin $\mathrm{He}^{3}$, and Qiang Zhang ${ }^{1}$ \\ ${ }^{1}$ Department of Earth System Science, Tsinghua University, Beijing 100084, China \\ ${ }^{2}$ Multiphase Chemistry Department, Max Planck Institute for Chemistry, 55128 Mainz, Germany \\ ${ }^{3}$ State Key Joint Laboratory of Environment Simulation and Pollution Control, School of Environment, \\ Tsinghua University, Beijing 100084, China \\ ${ }^{4}$ Institute for Environmental and Climate Research, Jinan University, Guangzhou 510630, China
}

Correspondence: Meng Li (m.li@mpic.de) and Qiang Zhang (qiangzhang@tsinghua.edu.cn)

Received: 14 March 2018 - Discussion started: 20 March 2018

Revised: 27 June 2018 - Accepted: 2 July 2018 - Published: 19 July 2018

\begin{abstract}
Reducing black carbon (BC) emissions has been recognized as an efficient way to simultaneously improve air quality and mitigate climate change. However, the benefits of $\mathrm{BC}$ emission controls are not well quantified, partly due to a lack of understanding of the changes in BC light absorption as a result of emission reductions. In this work, we discuss the effects of multi-pollutant emission reductions on $\mathrm{BC}$ light absorption based on a field campaign study conducted before, during and after the 2014 APEC (Asia-Pacific Economic Cooperation) meeting in Beijing, China. When emission restrictions were in place during APEC, we found that the reduction in the light absorption of $\mathrm{BC}$-containing particles was driven by both the decrease in $\mathrm{BC}$ mass concentration and the weakened light-absorption capability of BC. Compared with that before and after APEC, the daytime light absorption of BC-containing particles during APEC was reduced by $\sim 56 \%$, of which $\sim 48 \%$ was contributed by the decrease in $\mathrm{BC}$ mass concentration and the remaining $\sim 8 \%$ was contributed by a weakening of light-absorption capability for BC. Based on single-particle soot photometer (SP2) measurements and Mie calculations, we estimated that the light-absorption capability of $\mathrm{BC}$-containing particles with $\sim 80-200 \mathrm{~nm}$ refractory $\mathrm{BC}(\mathrm{rBC})$ cores in daytime during APEC was reduced by $\sim 6-15 \%$ and $\sim 10-20 \%$ compared with those before and after APEC, respectively. The decrease in BC light-absorption capability could be attributed to less coating material on $\mathrm{BC}$ surfaces as a result of the decreased chemical production of secondary aerosols. Compared with
\end{abstract}

that before and after APEC, the mass ratio between the coating materials and $\mathrm{rBC}$ core $(\sim 80-200 \mathrm{~nm})$ during APEC decreased by $\sim 10-30 \%$ and $\sim 31-53 \%$, respectively, due to reductions in coating precursor emissions, e.g., $\mathrm{SO}_{2}$ and $\mathrm{NO}_{2}$. The results reveal the benefits of emission control on BC light absorption by simultaneously reducing the mass concentration and light-absorption capability of BC, implying that synergetic reduction in multiple-pollutant emissions could benefit both air quality and climate.

\section{Introduction}

Black carbon (BC) has drawn considerable attention due to its key role in climate and the atmospheric environment (Bond and Sun, 2005; Jacobson et al., 2002, 2010). Because $\mathrm{BC}$ is the most efficient light-absorbing component in ambient aerosols (Bond and Bergstrom, 2006; Ramanathan and Carmichael, 2008), reduction measures targeting BC emissions have been recognized as a viable way to mitigate global warming (Shindell et al., 2012; Jacobson et al., 2010) and improve air quality in polluted regions (Ding et al., 2016; Z. Wang et al., 2018). The benefits of BC emission reduction are mainly driven by more solar radiation reaching the surface due to the reduction in BC light absorption in the atmosphere.

The light absorption of ambient $\mathrm{BC}$-containing particles can be reduced by decreasing the $\mathrm{BC}$ mass concentration, 
weakening the BC light-absorption capability or implementing both strategies. As primary aerosols, the mass concentration of BC particles generally decreases with emission reduction. When emission control measures were implemented, the mass concentration of the $\mathrm{BC}$ present in the atmosphere was proven to decrease (Han et al., 2015; Huang et al., 2010; $\mathrm{Xu}$ et al., 2015; J. K. Zhang et al., 2016). In terms of the influence of emission reduction on the characteristics of $\mathrm{BC}$ aerosols, previous studies usually highlighted the decrease in BC mass concentration (Han et al., 2015; Huang et al., 2010; J. K. Zhang et al., 2016). However, few studies have considered the change in the light-absorption capability of $\mathrm{BC}$-containing particles due to emission reduction.

The light-absorption capability of ambient BC-containing particles is closely associated with their aging degree (Jacobson et al., 2001; Liu et al., 2017; Moffet et al., 2009; Peng et al., 2016; Y. Zhang et al., 2016, 2018), i.e., the degree to which BC is internally mixed with other species (e.g., sulfate and nitrate; Oshima et al., 2009). When fresh BC is emitted from incomplete combustion (e.g., traffic emissions) other than biomass burning (Q. Wang et al., 2018; Pan et al., 2017), they are most likely externally mixed with other aerosol components (e.g., primary organic aerosol). These fresh BC particles exist as almost bare particles with few other species condensed on their surfaces and are called externally mixed BC particles (Jacobson et al., 2001; Chung et al., 2005). During atmospheric transport, fresh BC particles undergo aging, in which internally mixed $\mathrm{BC}$ particles form when other aerosol components coat the bare $\mathrm{BC}$ surface (Cheng et al., 2006; Bond and Bergstrom, 2006; Peng et al., 2016; Zhang et al., 2018). The internally mixed BC particles generally have a shell-and-core morphology, with the coating materials and $\mathrm{BC}$ as the shell and core, respectively. This shell-and-core morphology endows BC particles with a higher light-absorption capability because the coating materials act as a lens to focus more photons on BC (lensing effect, Lack and Cappa, 2010). Compared with externally mixed BC particles (i.e., bare BC), the light absorption of internally mixed $\mathrm{BC}$ particles (i,.e, coated BC) can be enhanced by a factor of 2-3 (Fuller et al., 1999; Jacobson et al., 2001; Schnaiter et al., 2005; Y. Zhang et al., 2016).

Emission reduction may affect the lensing effect by changing the amount of coating materials for the BC-containing particles and consequently altering the light-absorption capability of BC. Emission control measures can reduce the concentrations of not only $\mathrm{BC}$ but also co-emitted gaseous pollutants (e.g., volatile organic compounds (VOCs), $\mathrm{SO}_{2}$ and $\mathrm{NO}_{x}$ ) present in the atmosphere (Tang et al., 2015; Huang et al., 2015). The reduction in these secondary aerosol precursors can lower the production of secondary components (e.g., secondary organic matter, sulfate and nitrate) in aerosol particles (Cheng et al., 2008; Huang et al., 2010; Han et al., 2015). This relationship implies that the interaction between $\mathrm{BC}$ and secondary aerosol components via condensation and coagulation may be impacted by primary emission reduc- tions of both $\mathrm{BC}$ and co-emitted pollutants (e.g., VOCs, $\mathrm{SO}_{2}$ and $\mathrm{NO}_{x}$ ); in other words, emission control measures may influence $\mathrm{BC}$ aging in the atmosphere. As mentioned above, the aging degree of $\mathrm{BC}$-containing particles exerts a substantial effect on their light-absorption capability. Less-aged BC is expected as emission control measures are implemented to decrease BC light-absorption capability. However, it is still unclear whether emission control measures can lower the aging degree of $\mathrm{BC}$-containing particles and thus weaken their light-absorption capability.

In this work, we used the 2014 Asia-Pacific Economic Cooperation (APEC) meeting in Beijing, China as a case study to investigate the effects of emission control measures on the light absorption of ambient BC-containing particles. This paper reports in situ measurements before, during and after APEC and investigates how the concentrations of $\mathrm{BC}$ and coating precursors, the $\mathrm{BC}$ aging degree and the $\mathrm{BC}$ lightabsorption capability were affected by emission reductions. Based on these results, we quantified the impact of emission reduction during APEC on the light absorption of BCcontaining particles and further discuss the additional effect of emission control measures on $\mathrm{BC}$ light absorption due to changes in the coating materials of ambient $\mathrm{BC}$ particles.

\section{Methods and data}

\subsection{Measurement location and period}

The in situ measurements were carried out on the campus of Tsinghua University $\left(40^{\circ} 00^{\prime} 17^{\prime \prime} \mathrm{N}, 116^{\circ} 19^{\prime} 34^{\prime \prime} \mathrm{E}\right.$; Fig. S1 in the Supplement). The observation site is located in downtown Beijing, approximately $1 \mathrm{~km}$ from North 4th Ring Road, which has a high traffic density. The air quality at this site is considered typical of the Beijing urban environment. More details regarding the Tsinghua site can be found in Zheng et al. (2015) and Zhang et al. (2018).

The measurement period lasted from 28 October to 21 November 2014. A series of aggressive measures were implemented from 3-12 November 2014 in Beijing and the surrounding areas (i.e., Tianjin, Hebei, Shanxi, Shandong, Henan and Inner Mongolia; shown in Fig. S1) to achieve good air quality during the APEC meeting: mandatory restrictions on traffic flow in Beijing, limited or arrested production from high-emitting factories, suspended construction activities and bans on various outdoor burning practices (Gao et al., 2017; Huang et al., 2015; Tang et al., 2015; J. K. Zhang et al., 2016; L. Zhang et al., 2016). In this study, we classified the observation period into five subperiods: before APEC (28 October-2 November 2014), which served as a reference; during APEC (6-12 November 2014), which was characterized by the enforcement of emission control measures; after APEC (17-21 November 2014), which served as another reference; and two transition periods (3-5 and 13-16 November 2014), which are not discussed in this work considering that 
we could not distinguish the $\mathrm{BC}$ particles transported to the site during these days as characterized by the enforcement of emission control measures or not (Fig. S2 and the associated discussion in the Supplement).

\subsection{Instrumentation}

A single-particle soot photometer (SP2) instrument (Droplet Measurement Technologies, Boulder, CO, USA) uses a $1064 \mathrm{~nm} \mathrm{Nd}$ :YAG laser to measure the mass of a refractory BC $(\mathrm{rBC})$ core $\left(m_{\mathrm{rBC}}\right)$ and the scattering cross section $\left(C_{\mathrm{s}}\right)$ of an individual $\mathrm{BC}$-containing particle. As a light-absorbing component, an $\mathrm{rBC}$ core is gradually heated by the continuous laser beam and vaporizes at $\sim 4000 \mathrm{~K}$, the temperature at which detectable incandescent light is emitted (Schwarz et al., 2006; Moteki and Kondo, 2010). The incandescence signal recorded by SP2 was used to determine the $m_{\mathrm{rBC}}$ of an individual BC-containing particle. The mass concentration of $\mathrm{rBC}$ was calculated based on the $m_{\mathrm{rBC}}$ and sampling flow rate $\left(\sim 0.12 \mathrm{~L} \mathrm{~min}^{-1}\right.$, liters per minute). On the other hand, we used the scattering signal from the SP2 measurement to retrieve the $C_{\mathrm{s}}$ of an individual $\mathrm{BC}$-containing particle (including coating materials and $\mathrm{rBC}$ core) based on the leading-edge-only (LEO) method developed by Gao et al. (2007). The validity of the LEO method for ambient BCcontaining particles observed in China has been evaluated by Y. Zhang et al. (2016). More details on the SP2 technique have been reported elsewhere (Gysel et al., 2011; Pan et al., 2017; Sedlacek et al., 2012; Y. Zhang et al., 2016).

\subsection{Data analysis}

\subsubsection{Aging degree of $\mathrm{BC}$-containing particles}

The aging degree of ambient BC-containing particles was retrieved by the SP2 measurements (i.e., the $m_{\mathrm{rBC}}$ and the $C_{\mathrm{s}}$ of BC-containing particles) and Mie calculation. To quantify the aging degree of $\mathrm{BC}$-containing particles, we assumed that a BC-containing particle was a sphere with an $\mathrm{rBC}$ core and a non-refractory coating material (NR-CM) shell (Moteki and Kondo, 2007; Subramanian et al., 2010; Y. Zhang et al., 2016). The actual shape of BC-containing particles in the atmosphere is complex (He et al., 2015; Scarnato et al., 2013; Z. Wang et al., 2017). In this study, we focused on investigating $\mathrm{BC}$-containing particles during pollution episodes. Under polluted conditions, we have found fully aged BCcontaining particles in Beijing, China (Zhang et al., 2018). In our previous study (Y. Zhang et al., 2016), we found that the thickly coated BC particles in the North China Plain (including Beijing) exhibited a near-spherical shape, and the coreshell structure used in the Mie calculation was reasonable.

In this study, the diameter of the $\mathrm{rBC}$ core $\left(D_{\mathrm{c}}\right)$ and the whole particle diameter including the core and shell $\left(D_{\mathrm{p}}\right)$ were calculated to retrieve the aging degree of $\mathrm{BC}$-containing particles. $D_{\mathrm{c}}$ was calculated from $m_{\mathrm{rBC}}$ and the density of the
$\mathrm{rBC}$ core $\left(\rho_{\mathrm{c}}\right.$; here, a prescribed value of $\left.1.8 \mathrm{~g} \mathrm{~cm}^{-3}\right)$ (Cappa et al., 2012; Pan et al., 2017; Laborde et al., 2013). $D_{\mathrm{p}}$ was determined via the Mie calculation and was related to $D_{\mathrm{c}}$, the $C_{\mathrm{s}}$ of the BC-containing particle, and the refractive indices of NR-CM (RI $\mathrm{RI}_{\mathrm{NR}-\mathrm{CM}}, 1.5-0 i$; Zhang et al., 2018) and $\mathrm{rBC}$ core $\left(\mathrm{RI}_{\mathrm{c}}, 2.26-1.26 i\right.$; Taylor et al., 2015). The uncertainty of size information for the BC-containing particles from Mie calculation was estimated to be $\sim 10 \%$ in our previous work (Zhang et al., 2018). More details regarding the calculation of $D_{\mathrm{p}}$ and $D_{\mathrm{c}}$ for ambient BC-containing particles observed at the Tsinghua site can be found in Zhang et al. (2018).

In this study, the aging degree of a BC-containing particle was characterized by the mass ratio between NR-CM and $\mathrm{rBC}\left(m_{\mathrm{NR}-\mathrm{CM}} / m_{\mathrm{rBC}}\right)$ and was calculated by using Eq. (1):

$$
\frac{m_{\mathrm{NR}-\mathrm{CM}}}{m_{\mathrm{rBC}}}=\frac{\frac{1}{6} \times \pi \times\left(D_{\mathrm{p}}^{3}-D_{\mathrm{c}}^{3}\right) \times \rho_{\mathrm{NR}-\mathrm{CM}}}{m_{\mathrm{rBC}}},
$$

where $m_{\mathrm{NR}-\mathrm{CM}}$ is the mass of the non-refractory coating materials; $\rho_{\mathrm{NR}-\mathrm{CM}}$ is the density of the non-refractory coating materials, with a prescribed value of $1.4 \mathrm{~g} \mathrm{~cm}^{-3}$ in this study based on the composition of submicron aerosols during APEC reported by J. K. Zhang et al. (2016) and the densities of the various components (i.e., sulfate, nitrate, ammonium and organic aerosol; Cappa et al., 2012).

\subsubsection{Light absorption of BC-containing particles}

In this study, the light-absorption capability of ambient BC-containing particles was characterized by the lightabsorption enhancement $\left(E_{\mathrm{ab}}\right)$ of $\mathrm{BC}$ from the lensing effect caused by the coating materials. The $E_{\mathrm{ab}}$ of BC-containing particles was retrieved using a shell-and-core model based on Mie theory (Laborde et al., 2013; Metcalf et al., 2013; Schwarz et al., 2008) and calculated by dividing the lightabsorption cross section of the whole BC-containing particle $\left(C_{\mathrm{ab}, \mathrm{p}}\right)$ by that of the bare $\mathrm{rBC}$ core $\left(C_{\mathrm{ab}, \mathrm{c}}\right)$ at a certain wavelength (550 $\mathrm{nm}$ in this study), as expressed in Eq. (2):

$E_{\mathrm{ab}}=\frac{C_{\mathrm{ab}, \mathrm{p}}\left(D_{\mathrm{c}}, D_{\mathrm{p}}, \mathrm{RI}_{\mathrm{NR}-\mathrm{MC}}, \mathrm{RI}_{\mathrm{c}}\right)}{C_{\mathrm{ab}, \mathrm{c}}\left(D_{\mathrm{c}}, \mathrm{RI}_{\mathrm{c}}\right)}$,

where $C_{\mathrm{ab}, \mathrm{c}}$ and $C_{\mathrm{ab}, \mathrm{p}}$ were determined from the Mie calculation (uncertainty of $\sim 15 \%$ estimated in our previous study; Zhang et al., 2018). $C_{\mathrm{ab}, \mathrm{c}}$ is related to $D_{\mathrm{c}}$ and $\mathrm{RI}_{\mathrm{c}}$. For $C_{\mathrm{ab}, \mathrm{p}}$, we needed additional information on the whole particle, i.e., $D_{\mathrm{p}}$ and $\mathrm{RI}_{\mathrm{NR}-\mathrm{CM}}$.

The light-absorption coefficient $\left(\sigma_{\mathrm{ab}}\right)$ of BC-containing particles at a wavelength (550 and $670 \mathrm{~nm}$ used in this study) was determined by the light-absorption capability of $\mathrm{BC}$ and the $\mathrm{rBC}$ mass concentration $\left(C_{\mathrm{rBC}}\right)$, as shown in Eq. (3):

$\sigma_{\mathrm{ab}}=C_{\mathrm{rBC}} \times \mathrm{MAC}_{\mathrm{p}}=C_{\mathrm{rBC}} \times E_{\mathrm{ab}} \times \mathrm{MAC}_{\mathrm{c}}$,

where $\mathrm{MAC}_{\mathrm{p}}$ and $\mathrm{MAC}_{\mathrm{c}}$ are the mass absorption cross section (MAC) of BC-containing particles and $\mathrm{rBC}$ cores, respectively, which was calculated based on Mie theory and 


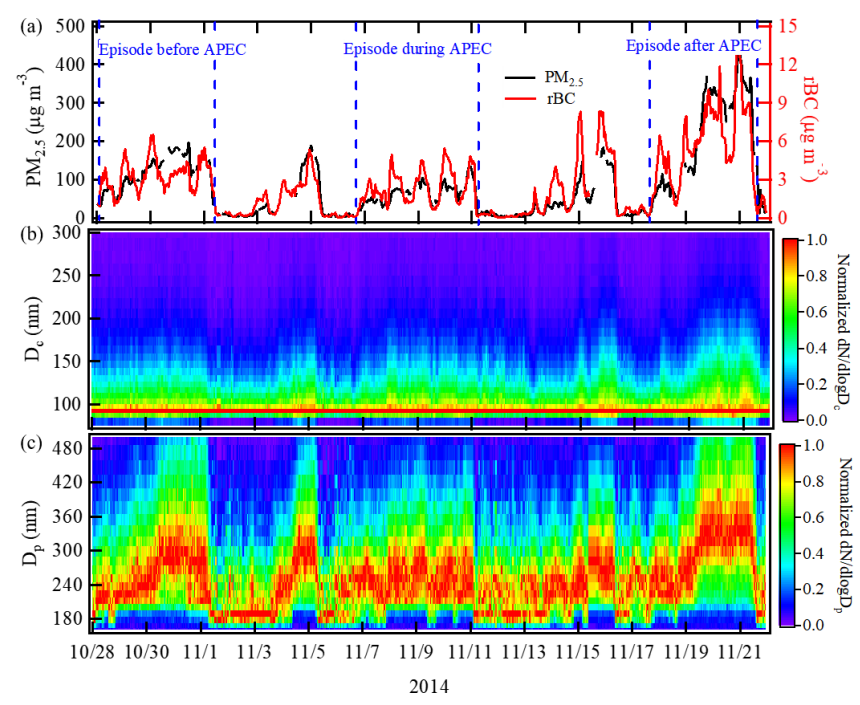

Figure 1. Time series of (a) the mass concentrations of $\mathrm{PM}_{2.5}$ and $\mathrm{rBC}$ and the number size distribution of (b) $\mathrm{rBC}$ cores $\left(D_{\mathrm{c}}\right)$ and (c) whole BC-containing particles $\left(D_{\mathrm{p}}\right)$.

SP2 measurements. In this study, the $\sigma_{\mathrm{ab}}$ at $670 \mathrm{~nm}$ was also obtained by a multi-angle absorption photometer (MAAP) measurement. The MAAP data were corrected using the algorithm reported by Hyvärinen et al. (2013).

\section{Results}

\subsection{Reduction in the concentrations of $\mathrm{BC}$ and coating precursors}

Figure 1a shows the time series of the $\mathrm{PM}_{2.5}$ and $\mathrm{rBC}$ mass concentrations during the campaign period. Three pollution episodes on 28 October-1 November and 6-11 and 17-21 November were observed before, during and after APEC, respectively. Following the APEC study in Sun et al. (2016), we focused on comparing the $\mathrm{BC}$ characteristics among the three pollution episodes to investigate the effect of emission reduction. During the three pollution episodes, the air masses over the site were mainly from the south and east of Beijing (Fig. S3), where emission control measures were implemented during APEC. On the other hand, the pollution episodes in Beijing were characterized by low wind speed and planetary boundary layer (PBL), as well as high relative humidity (Sun et al., 2016; Zheng et al., 2015).

The $\mathrm{PM}_{2.5}$ concentrations during the pollution episodes before and after APEC were $\sim 127$ and $\sim 213 \mu \mathrm{g} \mathrm{m}^{-3}$, respectively, which were larger than that $\left(\sim 66 \mu \mathrm{g} \mathrm{m}^{-3}\right)$ during APEC. The decrease in $\mathrm{PM}_{2.5}$ loadings revealed that the air quality was improved during APEC. Similarly, the rBC mass concentration during APEC was also smaller than those before and after APEC. However, the decreases in the rBC concentration during APEC by $\sim 27$ and $\sim 58 \%$, respec- tively, compared with before and after APEC were smaller than the corresponding decreases in the $\mathrm{PM}_{2.5}$ concentrations ( $\sim 48$ and $69 \%$, respectively), possibly indicating that more secondary aerosols (e.g., sulfate and nitrate) than primary aerosols (e.g., rBC) were reduced during APEC, which could aid the decrease in coating materials on BC surfaces.

Figure 2 compares the mass concentrations of both $\mathrm{rBC}$ and the coating precursors (i.e., $\mathrm{NO}_{2}$ and $\mathrm{SO}_{2}$ ) in the pollution episodes before, during and after APEC. Compared with that before and after APEC, the mass concentration of $\mathrm{NO}_{2}$ during APEC was decreased by $\sim 34$ and $\sim 45 \%$, respectively, while the $\mathrm{SO}_{2}$ concentration was reduced by $\sim 35$ and $\sim 67 \%$, respectively. These results revealed that the emission control measures implemented during APEC were a viable way to reduce not only the $\mathrm{rBC}$ mass concentrations but also the concentrations of secondary aerosol precursors present in the atmosphere. The emission-control-caused reduction in secondary particle precursors (i.e., $\mathrm{NO}_{2}$ and $\mathrm{SO}_{2}$ ) during APEC could have reduced the secondary aerosol formation in the atmosphere. Previous studies identified a reduction in the concentrations of secondary components (e.g., sulfate and nitrate) in aerosols during APEC compared to before and after APEC (J. K. Zhang et al., 2016; Han et al., 2015). However, the change in coating materials on the BC due to the reduction of secondary components was complex, which was not only determined by the decrease in $\mathrm{BC}$ versus secondary components, but also depends on secondary components condensed on BC-containing versus non-BC particles.

Figure $\mathrm{S} 4$ shows the diurnal variations in the $\mathrm{rBC}, \mathrm{NO}_{2}$ and $\mathrm{SO}_{2}$ concentration and the PBL during the pollution episodes before, during and after APEC. Comparing the diurnal variations between the $\mathrm{rBC}$ concentration and the PBL revealed that the $\mathrm{rBC}$ concentrations during the pollution episodes were dominated by the PBL. However, the precursor concentration of secondary aerosol (i.e., $\mathrm{NO}_{2}$ and $\mathrm{SO}_{2}$ ) during the pollution episodes exhibited different diurnal variations with a peak at noontime and early afternoon, which was most likely attributed to regional transport. The backtrajectory analysis (Fig. S3) revealed that the air mass during the pollution episodes was mainly from polluted regions (i.e., Hebei and Tianjin). This indicated that regional emission controls would reduce the pollutant (i.e., $\mathrm{rBC}, \mathrm{NO}_{2}$ and $\mathrm{SO}_{2}$ ) concentration in Beijing under polluted conditions. Sun et al. (2016) have demonstrated significant reductions in the precursors of secondary aerosol during APEC compared to those in the non-APEC period due to emission controls over a regional scale (i.e., Beijing and adjacent areas). The similar PBL (Fig. S4) during the pollution episodes before, during and after APEC further identified the important contribution of emission reduction to the decrease in $\mathrm{rBC}, \mathrm{NO}_{2}$ and $\mathrm{SO}_{2}$ concentration during APEC.

Previous studies have pointed out the importance of photochemical reactions in the $\mathrm{BC}$ aging process $(\mathrm{Q}$. Wang et al., 2017; Metcalf et al., 2013; Zhang et al., 2014; Peng et 

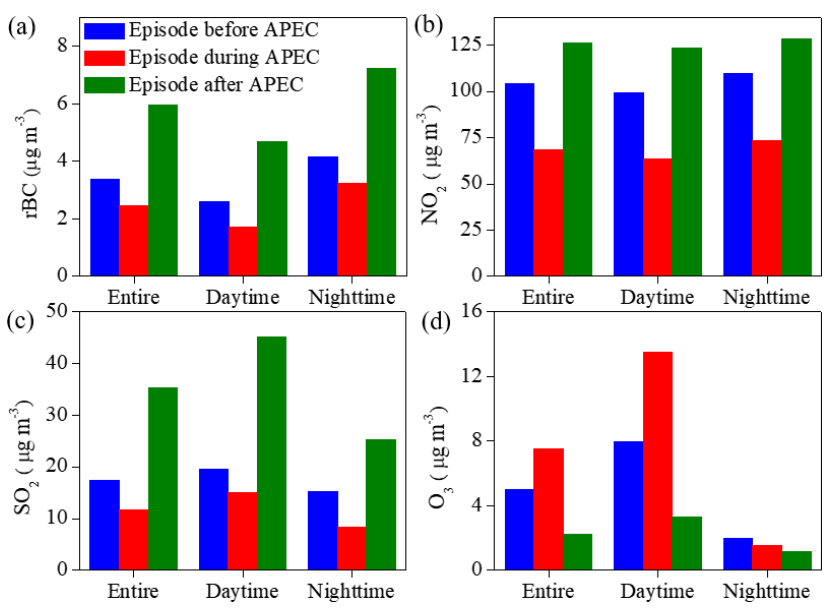

Figure 2. The mass concentrations of (a) $\mathrm{rBC}$, (b) $\mathrm{NO}_{2}$, (c) $\mathrm{SO}_{2}$ and (d) $\mathrm{O}_{3}$ for the pollution episodes before, during and after APEC. We separated the entire data sets into daytime (07:00 to 19:00 LT) and nighttime (19:00 to 07:00 LT of the following day) sets.

al., 2016), indicating that changing the daytime concentrations of $\mathrm{rBC}$ and coating precursors might play a more important role in affecting $\mathrm{BC}$ aging than altering the nighttime concentrations. We separated the data sets for the pollution episodes before, during and after APEC into daytime (07:00 19:00 LT) and nighttime (19:00 to 07:00 LT of the following day) sets. Figure 2 shows that while the emission controls were in place during APEC, a greater reduction in the $\mathrm{rBC}$ and $\mathrm{NO}_{2}$ concentrations occurred during the day than at night. Compared with those before and after APEC, the daytime reductions in the $\mathrm{NO}_{2}$ concentration during APEC were reduced by as much as $\sim 40$ and $\sim 51 \%$, respectively. By contrast, the daytime reduction $(\sim 25 \%)$ in the $\mathrm{SO}_{2}$ concentration during APEC compared with that before APEC was smaller than that at night, which might be attributable to the high contribution of regional emissions (e.g., power generation and industrial activities in Hebei Province) to the daytime $\mathrm{SO}_{2}$ concentration in Beijing (Guo et al., 2014; Tang et al., 2015). Meanwhile, a similar reduction $(\sim 67 \%)$ in the daytime and nighttime $\mathrm{SO}_{2}$ concentrations during APEC compared with that after APEC was observed. In summary, the significant reductions in the daytime levels of $\mathrm{rBC}$ and coating precursors during APEC further indicated that BC aging in the atmosphere might have been affected by the emission control measures.

\subsection{Reductions in the aging degree of $\mathrm{BC}$}

Figure $1 \mathrm{~b}$ and $\mathrm{c}$ show time series of the number size distribution of $\mathrm{rBC}$ cores $\left(D_{\mathrm{c}}\right)$ and whole $\mathrm{BC}$-containing particles $\left(D_{\mathrm{p}}\right)$, respectively. The $\mathrm{rBC}$ cores observed before, during and after APEC exhibited similar number size distributions, with a mode at $\sim 95 \mathrm{~nm}$ (Fig. 1b). The similar modes of the $\mathrm{rBC}$ cores could have resulted from similar emission sources for BC-containing particles observed before, during and after APEC. However, the whole BC-containing particles (including coating materials and $\mathrm{rBC}$ core) showed different number size distributions in the pollution episodes before, during and after APEC (Fig. 1c), indicating different amounts of coating materials on the $\mathrm{BC}$ surface during the three pollution episodes. In the pollution episodes before and after APEC, the particle size of the whole BC-containing particles exhibited sustained growth from $\sim 180$ to $\sim 320$ and $\sim 400 \mathrm{~nm}$, respectively, which could be attributed to the gradual condensation and coagulation of other species (i.e., primary aerosol and secondary components) on the $\mathrm{BC}$ surface. However, the continuous size growth of the whole $\mathrm{BC}$-containing particles was not observed in the pollution episode during APEC, in which the number particle size distribution was with a mode no more than $\sim 280 \mathrm{~nm}$ (Fig. 1c), significantly smaller than those before $(\sim 320 \mathrm{~nm})$ and after APEC $(\sim 400 \mathrm{~nm})$. These results indicated that secondary formation during APEC was insufficient to maintain continuous BC aging.

Figure 3 compares the mass ratio between the coating materials and $\mathrm{rBC}$ cores $\left(m_{\mathrm{NR}-\mathrm{CM}} / m_{\mathrm{rBC}}\right)$ for $\mathrm{BC}$ containing particles with size-resolved $\mathrm{rBC}$ cores in the pollution episodes before, during and after APEC. The $m_{\mathrm{NR}-\mathrm{CM}} / m_{\mathrm{rBC}}$ ratios of $\mathrm{BC}$-containing particles before, during and after APEC showed similar correlations with the $\mathrm{rBC}$ core size; namely, the $m_{\mathrm{NR}-\mathrm{CM}} / m_{\mathrm{rBC}}$ ratio decreased with increasing rBC core size (Fig. 3a). The size-dependent $m_{\mathrm{NR}-\mathrm{CM}} / m_{\mathrm{rBC}}$ ratio of $\mathrm{BC}$-containing particles indicated that particle growth was more effective for smaller particles, which followed the diffusion-controlled growth law (Seinfeld and Pandis, 2006). At a certain size of rBC cores, Fig. 3a shows that the $m_{\mathrm{NR}-\mathrm{CM}} / m_{\mathrm{rBC}}$ ratio of ambient $\mathrm{BC}$ containing particles during APEC was significantly smaller than those before and after APEC, revealing that the emission restrictions during APEC weakened the condensation of other species on the $\mathrm{BC}$ surface. For ambient $\mathrm{BC}$-containing particles with $\sim 80-200 \mathrm{~nm} \mathrm{rBC}$ cores, the $m_{\mathrm{NR}-\mathrm{CM}} / m_{\mathrm{rBC}}$ ratios observed in the pollution episodes before, during and after APEC were 4-22, 3-15 and 5-33, respectively.

Figure $3 \mathrm{~b}$ shows the reductions in the $m_{\mathrm{NR}-\mathrm{CM}} / m_{\mathrm{rBC}}$ ratios of BC-containing particles for the pollution episodes during APEC compared with those before and after APEC, which were also dependent on $\mathrm{rBC}$ core size. Smaller rBC cores exhibited greater reductions in the $m_{\mathrm{NR}-\mathrm{CM}} / m_{\mathrm{rBC}}$ ratio as a result of emission control measurements during APEC. This indicated that in terms of $\mathrm{BC}$ aging, it was more sensitive to emission levels for smaller rBC cores. This could be explained by the diffusion-controlled growth law; i.e., the growth of smaller BC particles was more effective (Metcalf et al., 2013; Seinfeld and Pandis, 2006), and thus the effect of emission reduction on $\mathrm{BC}$ aging was more significant for smaller $\mathrm{rBC}$ particles. Compared with that before and after APEC, the $m_{\mathrm{NR}-\mathrm{CM}} / m_{\mathrm{rBC}}$ ratio of ambient BC-containing particles with $\sim 80-200 \mathrm{~nm} \mathrm{rBC}$ cores during APEC was reduced by $\sim 10-30$ and $\sim 31-53 \%$, respectively. The rela- 

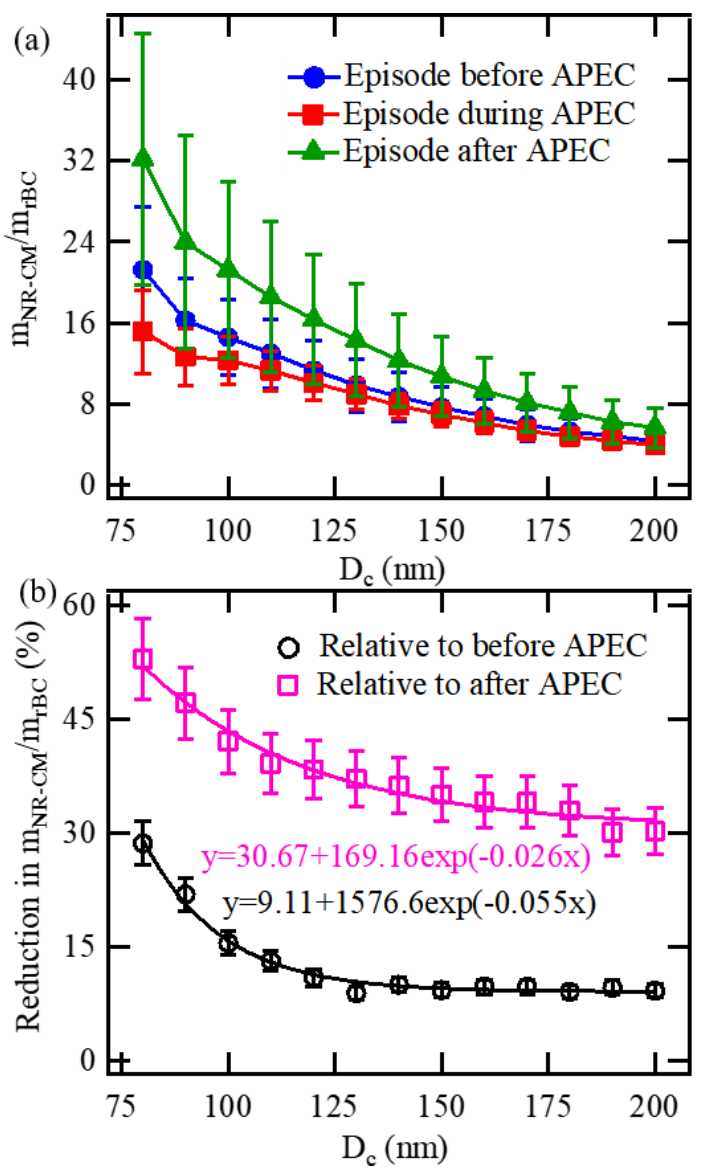

Figure 3. Comparison of the aging degree of BC-containing particles for the pollution episodes before, during and after APEC: (a) the $m_{\mathrm{NR}-\mathrm{CM}} / m_{\mathrm{rBC}}$ ratio of BC-containing particles and (b) the reduction in the $m_{\mathrm{NR}-\mathrm{CM}} / m_{\mathrm{rBC}}$ ratio of BC-containing particles during APEC relative to those before and after APEC.

tionship between the reduction in the $m_{\mathrm{NR}-\mathrm{CM}} / m_{\mathrm{rBC}}$ ratio of BC-containing particles $\left(R_{\text {aging }}\right)$ during APEC and their $\mathrm{rBC}$ core size $\left(D_{\mathrm{c}}\right)$ followed an exponential function (Fig. 3b), i.e., $R_{\text {aging }}=9.1+1576.6 \exp \left(-0.055 D_{\mathrm{c}}\right)$ (relative to that before APEC) and $R_{\text {aging }}=30.7+169.2 \exp \left(-0.025 D_{\mathrm{c}}\right)$ (relative to that after APEC).

The reduction in the $m_{\mathrm{NR}-\mathrm{CM}} / m_{\mathrm{rBC}}$ ratio of $\mathrm{BC}$ containing particles for the pollution episode during APEC relative to that before and after APEC showed pronounced diurnal cycles (Fig. 4). Compared with that before APEC, the reduction in the $m_{\mathrm{NR}-\mathrm{CM}} / m_{\mathrm{rBC}}$ ratio of BC-containing particles with 80-200 nm rBC cores during APEC showed maxima in the afternoon ( $\sim$ 14:00-17:00 LT; Fig. 4a), consistent with the peak time of the diurnal cycle of $\mathrm{O}_{3}$ concentrations before and during APEC (Fig. 4c). This consistency indicated that the reduction in coating materials on the $\mathrm{BC}$ surface during APEC compared to that before APEC was most likely dominated by the lower photochemical production of secondary species. Figure 5a1 shows that the reduc-

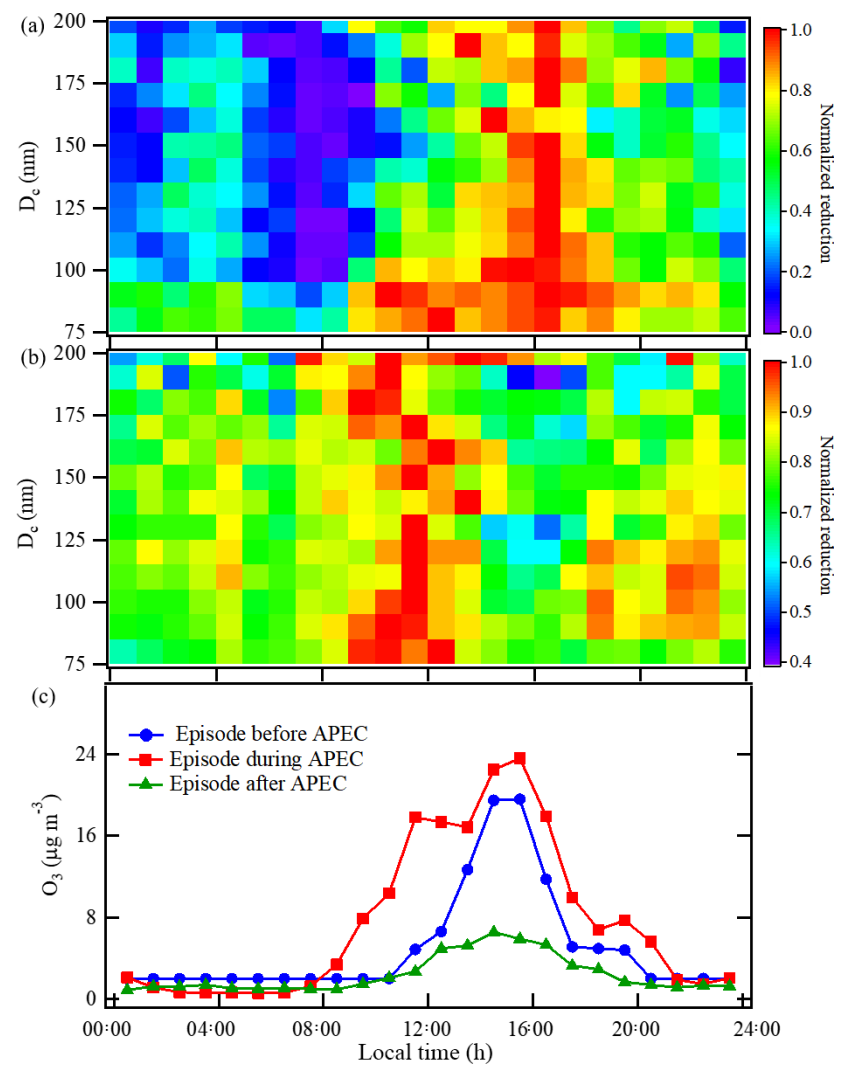

Figure 4. Diurnal cycle of the normalized reduction in the $m_{\mathrm{NR}-\mathrm{CM}} / m_{\mathrm{rBC}}$ ratio of $\mathrm{BC}$-containing particles for the pollution episode during APEC relative to those (a) before and (b) after APEC. (c) Diurnal cycle of $\mathrm{O}_{3}$ concentration for the pollution episodes before, during and after APEC.

tion in the $m_{\mathrm{NR}-\mathrm{CM}} / m_{\mathrm{rBC}}$ ratio of BC-containing particles during APEC relative to that before APEC increases with the $\mathrm{O}_{3}$ concentration during the day $(07: 00-19: 00 \mathrm{LT})$, revealing that the effect of emission controls on $\mathrm{BC}$ aging is associated with photochemistry. Moreover, Fig. 4a shows the diurnal cycle of the reduction in the $m_{\mathrm{NR}-\mathrm{CM}} / m_{\mathrm{rBC}}$ ratio of BCcontaining particles during APEC compared to that before APEC with minima during rush hour $(\sim 06: 00-08: 00 \mathrm{LT})$, which can be due to a larger contribution of primary emissions of fresh BC (namely, bare BC and thin-coated BC particles) during rush hour than at other times for both episodes before and during APEC.

However, the reduction in the $m_{\mathrm{NR}-\mathrm{CM}} / m_{\mathrm{rBC}}$ ratio of $\mathrm{BC}$ containing particles for the pollution episode during APEC compared to that after APEC showed a different diurnal cycle, with maxima at $\sim 10: 00-12: 00 \mathrm{LT}$ and with minima at $\sim$ 15:00-17:00 LT (Fig. 4b). Figure 4c shows that the daytime $\mathrm{O}_{3}$ concentrations after APEC are significantly smaller than those during APEC, indicating a weakened contribution from photochemistry after APEC. The increased amount of coating materials of $\mathrm{BC}$ observed after APEC compared to that during APEC was mostly likely attributed to enhanced 
(a)
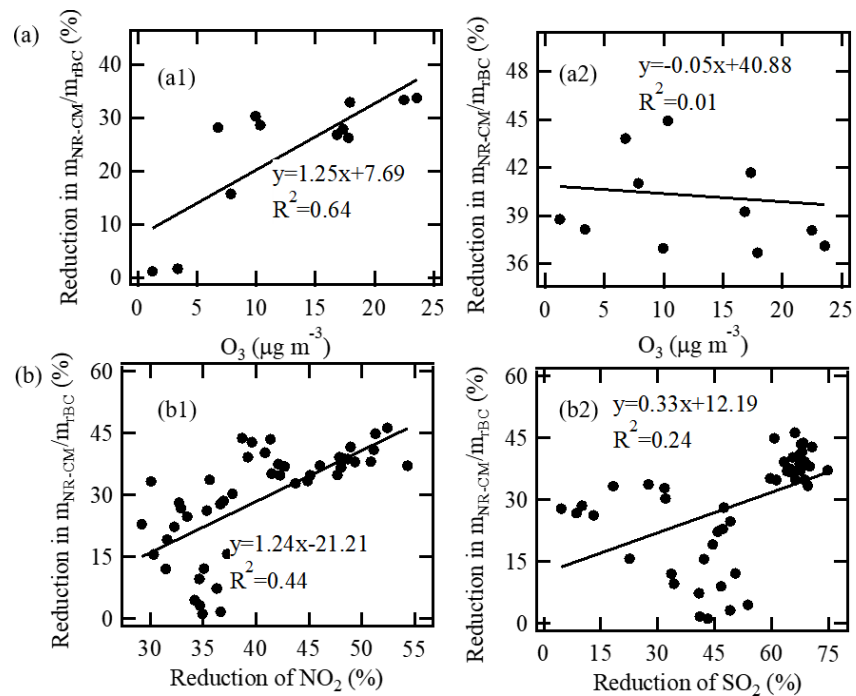

$\mathrm{O}_{3}\left(\mu \mathrm{g} \mathrm{m}^{-3}\right)$

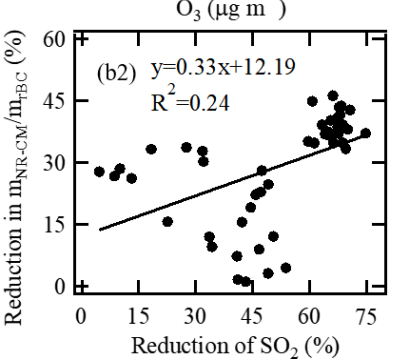

Figure 5. (a) Correlation between the reduction in the $m_{\mathrm{NR}-\mathrm{CM}} / m_{\mathrm{rBC}}$ ratio of $\mathrm{BC}$-containing particles for the pollution episode during APEC relative to those (a1) before and (a2) after APEC and the daytime (07:00-19:00) $\mathrm{O}_{3}$ concentration during APEC. (b) Correlation between the reduction in $m_{\mathrm{NR}-\mathrm{CM}} / m_{\mathrm{rBC}}$ during APEC relative to those before and after APEC and the corresponding reduction in the concentrations of (b1) $\mathrm{NO}_{2}$ and (b2) $\mathrm{SO}_{2}$

other reactions (e.g., heterogeneous chemistry) during haze episodes (Xie et al., 2015; Yang et al., 2015; Zheng et al., 2015; Mu et al., 2018). Figure $5 \mathrm{a} 2$ shows that the variation in the reduction in the $m_{\mathrm{NR}-\mathrm{CM}} / m_{\mathrm{rBC}}$ ratio of BC-containing particles during APEC compared to that after APEC is poorly correlated with the $\mathrm{O}_{3}$ concentration. The diurnal trend of the reduction in the $m_{\mathrm{NR}-\mathrm{CM}} / m_{\mathrm{rBC}}$ ratio of BC-containing particles during APEC relative to that after APEC was likely driven by the simultaneous effects of enhanced photochemistry and weakened other chemistry (e.g., heterogeneous reaction) contributions during APEC.

As discussed above, the reduction in the aging degree of ambient BC-containing particles during APEC could have been caused by the decreased chemical production (namely, weakened contributions from photochemical or other reactions) of coating materials on the $\mathrm{BC}$ surface. Figure $5 \mathrm{~b}$ shows that the reduction in the $\mathrm{m}_{\mathrm{NR}-\mathrm{CM}} / m_{\mathrm{rBC}}$ ratio of $\mathrm{BC}-$ containing particles during APEC relative to that before and after APEC is associated with a decrease of the concentrations of $\mathrm{SO}_{2}$ and $\mathrm{NO}_{2}$ due to emission reduction. A greater decrease in the concentrations of $\mathrm{SO}_{2}$ and $\mathrm{NO}_{2}$ corresponded to a greater reduction in the $m_{\mathrm{NR}-\mathrm{CM}} / m_{\mathrm{rBC}}$ ratio of $\mathrm{BC}$ containing particles during APEC. The reduction in precursor emissions of secondary species (e.g., $\mathrm{SO}_{2}$ and $\mathrm{NO}_{2}$ ) could decrease the chemical production, and therefore lower amounts of coating materials on the BC surfaces were observed during APEC.

\subsection{Reduction in the light absorption of BC-containing particles}

The reduction in the $\mathrm{BC}$ aging degree during APEC could weaken the light-absorption capability of BC-containing particles owing to a decrease in the lensing effect caused by less coating material on the BC surfaces (Fuller et al., 1999; Lack and Cappa, 2010). Figure 6 compares the $E_{\mathrm{ab}}$ of BCcontaining particles during the day for the pollution episodes observed before, during and after APEC. The daytime $E_{\mathrm{ab}}$ of BC-containing particles with $80-200 \mathrm{~nm} \mathrm{rBC}$ cores varied from $\sim 1.5$ to $\sim 2.5$ during APEC, values that were remarkably lower than before and after APEC (i.e., $E_{\mathrm{ab}}$ of 1.7-3.0 and 1.8-3.2, respectively; Fig. 6a); these results reflected a weakened light-absorption capability of $\mathrm{BC}$ during APEC. The reduction in the daytime $E_{\mathrm{ab}}$ of $\mathrm{BC}$-containing particles $\left(R_{E \mathrm{ab}}\right)$ during APEC compared with those before and after APEC decreased with the $\mathrm{rBC}$ core size $\left(D_{\mathrm{c}}\right)$, and the relationship followed an exponential function $\left(R_{E \mathrm{ab}}=\right.$ $6.3+192.9 \exp \left(-0.039 D_{\mathrm{c}}\right)$ relative to that before APEC and $R_{E \mathrm{ab}}=9.8+148.8 \exp \left(-0.033 D_{\mathrm{c}}\right)$ relative to that after APEC), as shown in Fig. 6b. Compared with before and after APEC, the $E_{\mathrm{ab}}$ of BC-containing particles with $\sim 80$ $200 \mathrm{~nm}$ rBC cores during the day decreased by $\sim 6-15$ and $\sim 10-20 \%$, respectively. Our results provide evidence that emission controls could weaken the light-absorption capability of ambient BC-containing particles. This weakening would have enhanced the effects of emission control measures during APEC on BC light absorption.

Figure $7 \mathrm{a}$ shows the measured and theoretical lightabsorption coefficient of BC-containing particles during the campaign period. The measured $\sigma_{\mathrm{ab}}$ revealed that the daytime light absorption of BC-containing particles in the pollution episode during APEC decreased by $\sim 42$ and $\sim 68 \%$ compared with those in pollution episodes before and after APEC, respectively. This decrease could be attributed to the reduction in both the $\mathrm{rBC}$ mass concentration and the lightabsorption capability of ambient BC-containing particles. In order to separate the contributions of a decrease in $\mathrm{rBC}$ mass concentration and a weakening of $\mathrm{BC}$ light-absorption capability to the reduction in light absorption during APEC, we calculated the theoretical reduction in $\sigma_{\mathrm{ab}}$ of BC-containing during APEC with and without considering the weakened light-absorption capability of BC-containing particles due to emission reduction ( $\sigma_{\mathrm{ab} \text {, with }}$ and $\sigma_{\mathrm{ab} \text {, without }}$, respectively). When considering the simultaneous reduction in the mass concentration and light-absorption capability of $\mathrm{BC}$, the calculated reduction in the daytime $\sigma_{\mathrm{ab}}$ of BC-containing particles during APEC related to non-APEC period showed a good agreement with ones obtained from MAAP measurements (Fig. 7b). This agreement demonstrated that the decrease in the light absorption of BC-containing particles depended not only on the reduction of $\mathrm{BC}$ mass concentration, but also on the weakening of their light-absorption capability. 

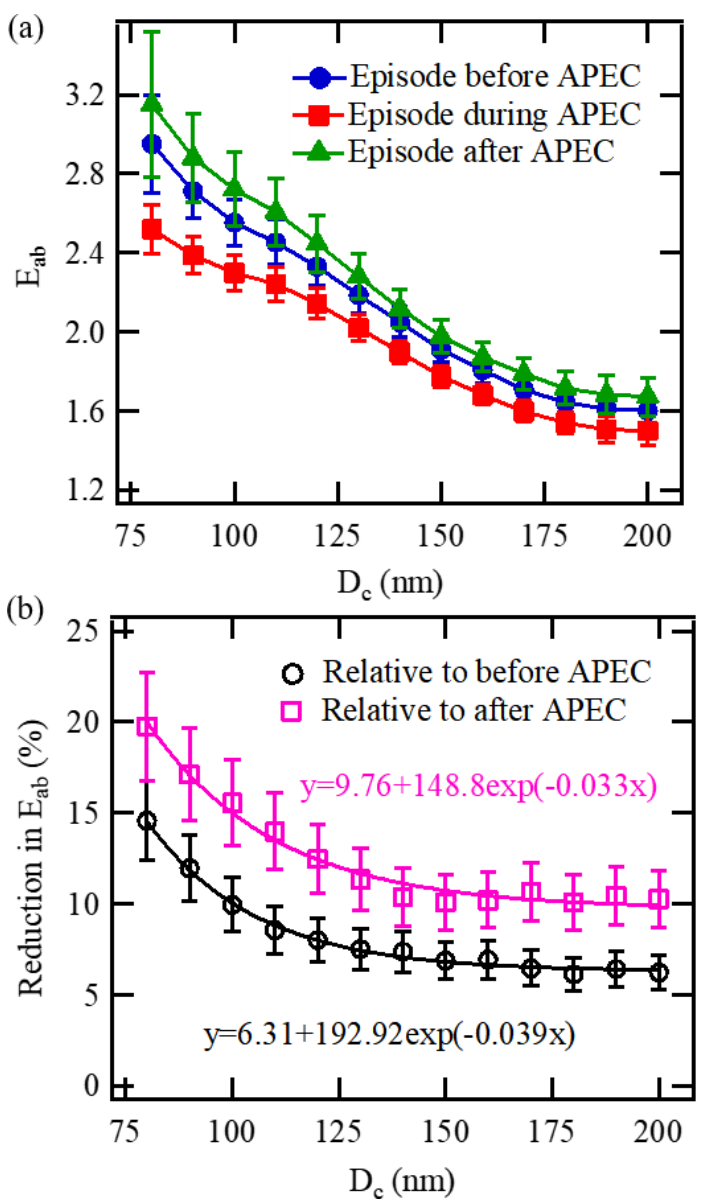

Figure 6. Comparison of the light-absorption capability of BCcontaining particles during the day for the pollution episodes before, during and after APEC: (a) light-absorption enhancement $\left(E_{\mathrm{ab}}\right)$ of $\mathrm{BC}$-containing particles and (b) the reduction in $E_{\mathrm{ab}}$ of $\mathrm{BC}$ containing particles during APEC relative to those before and after APEC.

Considering the reductions in both the mass concentration and light-absorption capability of $\mathrm{BC}$ due to emission control measures, the daytime light absorption of BC-containing particles (i.e., $\sigma_{\mathrm{ab} \text {, with }}$ ) decreased by $\sim 41$ and $\sim 68 \%$ during APEC compared to those before and after APEC, respectively. However, the $\sigma_{\mathrm{ab} \text {, without }}$ of BC during APEC decreased by $\sim 34$ and $\sim 62 \%$ relative to that before and after APEC, respectively (Fig. 7b). The difference between the reductions in $\sigma_{\mathrm{ab} \text {, with }}$ and $\sigma_{\mathrm{ab}}$, without indicated that the reduction in the $\mathrm{rBC}$ concentration contributed $\sim 83$ and $\sim 91 \%$ of the reduction in $\mathrm{BC}$ light absorption during APEC compared to before and after APEC, respectively, while the weakening of the BC light-absorption capability contributed $\sim 17$ and $\sim 9 \%$, respectively. On average, the light absorption of BC-containing particles in daytime during APEC decreased by $\sim 56 \%$ compared with before and after APEC, of which $\sim 48 \%$ was contributed by the reduction in the mass concentration of $\mathrm{rBC}$ and the remaining $\sim 8 \%$ was controlled by the

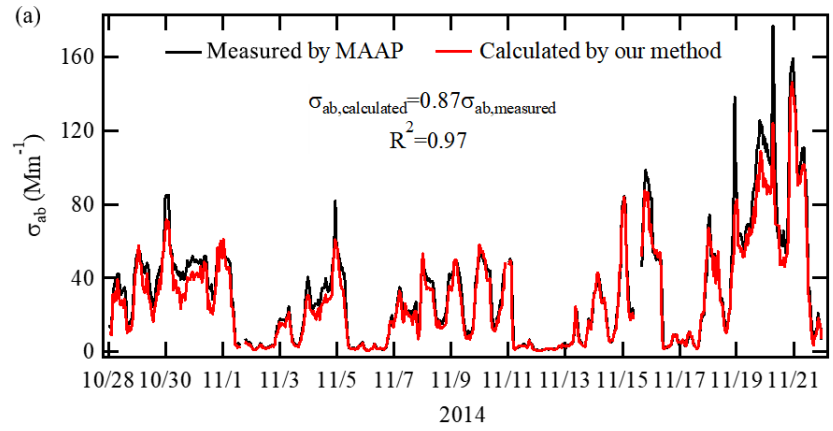

(b)

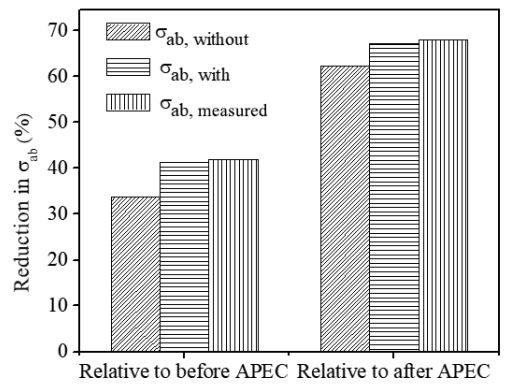

Figure 7. (a) The light-absorption coefficient $\left(\sigma_{\mathrm{ab}}\right)$ at $670 \mathrm{~nm}$. (b) Reduction in the absorption coefficients $\left(\sigma_{\mathrm{ab}}\right)$ of BC-containing particles observed in the pollution episode during APEC relative to those before and after APEC. The correlation between the calculated $\sigma_{\mathrm{ab}}\left(\sigma_{\mathrm{ab} \text {,calculated }}\right)$ using Mie theory combined with SP2 measurements and the measured $\sigma_{\mathrm{ab}}\left(\sigma_{\mathrm{ab} \text {,measured }}\right)$ by MAAP is also shown in (a). The $\sigma_{\mathrm{ab}}$,with and $\sigma_{\mathrm{ab}}$,without values represent $\sigma_{\mathrm{ab}, \text { calculated }}$ values with and without, respectively, considering the differences in the light-absorption capability of ambient BCcontaining particles among the episodes before, during and after APEC.

weakening of BC light-absorption capability. These results imply that reductions in the emission of multiple pollutants (i.e., BC and precursors of secondary species) in China could benefit air quality and climate due to significantly lowering the light absorption of $\mathrm{BC}$, which was driven by reductions in both $\mathrm{rBC}$ mass concentration and the light-absorption capability of BC-containing particles.

\section{Discussion}

Based on a comparison of the observations before, during and after APEC, we found that the emission control measures successfully reduced both the $\mathrm{rBC}$ mass concentration and the light-absorption capability (i.e., $E_{\mathrm{ab}}$ ) of BCcontaining particles, resulting in a significant decrease in the light absorption of $\mathrm{BC}$. The mechanism underlying the effect of the emission reductions during APEC on BC light absorption is summarized in Fig. 8. Emission control measures reduce the amount of both $\mathrm{BC}$ and co-emitted secondary aerosol precursors present in the atmosphere. The presence of lower amounts of secondary particle precursors in the atmosphere weakens the chemical formation of sec- 


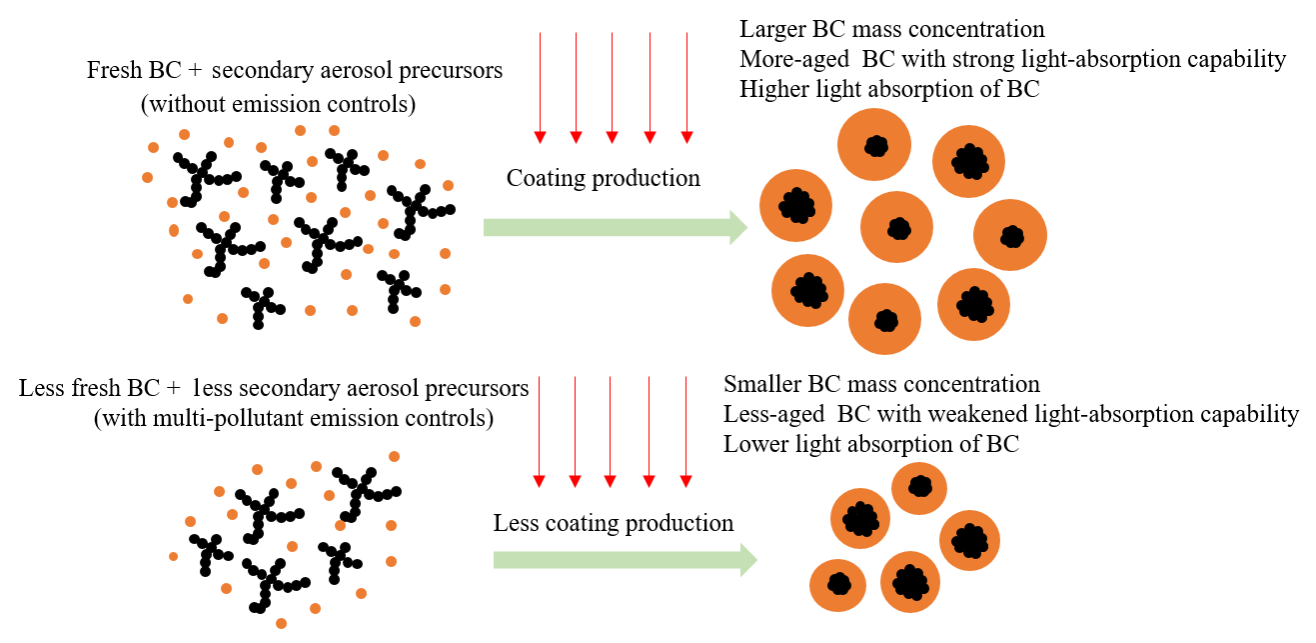

Figure 8. Conceptual scheme of the reduction in light absorption of BC-containing particles due to multi-pollutant emission controls.

ondary aerosol components, suppressing the condensation of secondary species on BC surfaces. Less coating material on $\mathrm{BC}$ can weaken the lensing effect, which leads to a weakening of the light-absorption capability for BC-containing particles. Simultaneous reductions in the mass concentration and light-absorption capability of BC can result in a much lower light absorption of $\mathrm{BC}$ during APEC compared to before and after APEC.

In China, a series of emission controls measures have been implemented in pollution regions (e.g., Jing-Jin-Ji region) aiming to increase the number of clean days and decrease the number of haze days. This comparison between periods with and without emission control measures may illustrate the differences between clean and polluted periods. In terms of different pollution levels in China, our findings imply that a clean period is characterized by not only a lower BC mass concentration but also a weaker light-absorption capability of BC-containing particles compared to that in polluted periods. In our previous study (Zhang et al., 2018), we found that the light-absorption capability of ambient BC-containing particles observed in Beijing was enhanced by an increase in pollution levels, resulting in an amplification of BC light absorption under polluted conditions. The present work clearly demonstrates that emission control measures can reduce this amplification effect by decreasing the light-absorption capability of BC-containing particles. Moreover, this work can explain how emission control measures reduce the amplification effect, namely by slowing the aging of $\mathrm{BC}$ resulting from a reduction in co-emitted secondary aerosol precursors (e.g., $\mathrm{SO}_{2}, \mathrm{NO}_{x}$ and VOCs).

The simultaneous reductions in the mass concentration and light-absorption capability of BC due to emission controls confirmed the suggestions of previous studies that $\mathrm{BC}$ emission reductions could achieve multiple benefits, i.e., simultaneously controlling air pollution and protecting the climate (Ding et al., 2016). Furthermore, our study implies that the air quality and climate co-benefits of multi-pollutant emission controls are enhanced by the weakened lightabsorption capability of BC-containing particles. In terms of air quality improvement, weakened light-absorption capability plays an important role in both the direct and indirect effects of BC. Weakened light-absorption capability can directly lower the light-absorbing efficiency of $\mathrm{BC}$ aerosols in the atmosphere, resulting in more solar light radiation reaching the surface; the weakened light-absorption capability of ambient BC-containing particles can indirectly mitigate air pollution by improving PBL suppression driven by the dome effect of BC (Ding et al., 2016; Z. Wang et al., 2017). On the other hand, an enhanced reduction in climate warming can be attributed to a smaller direct radiative forcing from $\mathrm{BC}$ aerosols due to a weaker light-absorption capability of atmospheric BC-containing particles. The importance of the weakened light-absorption capability of BC highlighted in our study provides clues for the management of air quality and climate change. The emission controls of multiple pollutants including BC and co-emitted secondary aerosol precursors may be an efficient way to simultaneously mitigate air pollution and climate warming.

\section{Concluding remarks}

The effects of emission reductions on the light absorption of $\mathrm{BC}$-containing particles are not only controlled by the reduction in the BC mass concentration but also dependent on the change in their light-absorption capability. The decrease in the $\mathrm{BC}$ mass concentration due to emission control measures is well known. However, the impact of emission reduction on the light-absorption capability of BC-containing particles remains unclear due to a lack of available observations. The 2014 APEC meeting in Beijing, China provides an invaluable opportunity to measure the variations in the light-absorption capability of ambient BC-containing particles due to emis- 
sion reductions. In this work, based on in situ measurements at an urban site in Beijing before, during and after APEC using an SP2 technique, we explored whether and how emission control measures in China influence the light-absorption capability of ambient BC-containing particles. Note that this comparative study focused on the pollution episodes before, during and after APEC.

We found that the emission control measures successfully lowered the aging degree (i.e., $m_{\mathrm{NR}-\mathrm{CM}} / m_{\mathrm{rBC}}$ ) of BC-containing particles. The $m_{\mathrm{NR}-\mathrm{CM}} / m_{\mathrm{rBC}}$ ratio of $\mathrm{BC}$ containing particles with $\sim 80-200 \mathrm{~nm}$ rBC cores during APEC decreased by $\sim 10-30$ and $\sim 31-53 \%$ compared to that before and after APEC, respectively. The reduction in the $m_{\mathrm{NR}-\mathrm{CM}} / m_{\mathrm{rBC}}$ ratio of $\mathrm{BC}$-containing particles increased with decreasing $\mathrm{rBC}$ core size, following an exponential function. The size-dependent reduction in the $m_{\mathrm{NR}-\mathrm{CM}} / m_{\mathrm{rBC}}$ ratio of $\mathrm{BC}$-containing particles indicated that emission reduction was more effective for slowing the aging of smaller $\mathrm{rBC}$ particles. The reduction in the $m_{\mathrm{NR}-\mathrm{CM}} / m_{\mathrm{rBC}}$ ratio of $\mathrm{BC}$-containing particles during APEC relative to those before and after APEC showed a pronounced diurnal cycle, with maxima at $\sim 14: 00-17: 00$ and $\sim$ 10:00-12:00 LT, respectively. The decreased aging of BCcontaining particles during APEC was mainly driven by a reduction in chemical production (i.e., oxidation products such as sulfate and nitrate) on the surface of $\mathrm{BC}$ due to lower amounts of secondary aerosol precursors (e.g., the $\mathrm{NO}_{2}$ concentration during APEC decreased by $~ 34$ and $\sim 45 \%$ compared with those before and after APEC, respectively, and the corresponding $\mathrm{SO}_{2}$ concentration decreased by $\sim 35$ and $\sim$ $67 \%$ during APEC, respectively) present in the atmosphere during $\mathrm{BC}$ aging. The reduction in the $m_{\mathrm{NR}-\mathrm{CM}} / m_{\mathrm{rBC}}$ ratio of $\mathrm{BC}$-containing particles during APEC relative to those before and after APEC increased with the reduction in the concentrations of $\mathrm{NO}_{2}$ and $\mathrm{SO}_{2}$.

Due to the lower amount of coating materials on BC surfaces during APEC, the light-absorption capability (i.e., $E_{\mathrm{ab}}$ ) of BC-containing particles with $\sim 80-200 \mathrm{~nm}$ rBC cores during the day decreased by $\sim 6-15$ and $\sim 10-20 \%$ compared to those before and after APEC, respectively. The weakened light-absorption capability of BC-containing particles enhanced the reduction in $\mathrm{BC}$ light absorption due to the emission control measures. When considering the reduction in both the mass concentration and light-absorption capability of BC-containing particles during the day during APEC, the theoretical light absorption (i.e., $\sigma_{\mathrm{ab}}$ ) decreased by $\sim 41$ and $\sim 68 \%$ compared to those before and after APEC, respectively. However, the reduced light absorption of BC during the day caused by the decrease in the $\mathrm{BC}$ mass concentration during APEC compared to before and after APEC was estimated to be $\sim 34$ and $\sim 62 \%$, respectively. Therefore, $\sim 10-20 \%$ of the reduction in the daytime light absorption of BC-containing particles during APEC relative to those before and after APEC could be attributed to the weakened light-absorption capability. Our study revealed that re- ductions in the emissions of multiple pollutants (i.e., BC, $\mathrm{NO}_{2}$ and $\mathrm{SO}_{2}$ ) could reduce the light-absorption capability of BC. Weakened light-absorption capability of BC due to emission controls further confirmed the suggestions of previous studies that $\mathrm{BC}$ emission reductions can achieve multiple benefits, i.e., simultaneously controlling air pollution and protecting the climate (Ding et al., 2016; Peng et al., 2016; Zhang et al., 2018). Our study implies that the air quality and climate co-benefits of multi-pollutant emission control could be enhanced by the weakened light-absorption capability of BC-containing particles.

Data availability. The observational data used in this study can be provided upon request to Yuxuan Zhang (yuxuan.zhang@mpic.de) and Qiang Zhang (qiangzhang@tsinghua.edu.cn).

Supplement. The supplement related to this article is available online at: https://doi.org/10.5194/acp-18-10275-2018-supplement.

Author contributions. YuZ and QZ designed the research. YuZ and HL performed the field measurements. YiZ and GG processed auxiliary air quality and meteorological data. YuZ developed the model for analyzing the aging degree and light absorption of black carbon. YuZ, XL, ML and QZ interpreted the data. YuZ and ML wrote the paper with input from all coauthors.

Competing interests. The authors declare that they have no conflict of interest.

Acknowledgements. This work was funded by the National Natural Science Foundation of China (41625020, 41571130035 and 91644218) and the Guangdong "Pearl River Talents Plan" (2016ZT06N263).

The article processing charges for this open-access publication were covered by the Max Planck Society.

Edited by: Aijun Ding

Reviewed by: two anonymous referees

\section{References}

Bond, T. C. and Sun, H.: Can Reducing Black Carbon Emissions Counteract Global Warming?, Environ. Sci. Technol., 39, 59215926, 2005.

Bond, T. C. and Bergstrom, R. W.: Light Absorption by Carbonaceous Particles: An Investigative Review, Aerosol Sci. Technol., 40, 27-67, 2006.

Cappa, C. D., Onasch, T. B., Massoli, P., Worsnop, D. R., Bates, T. S., Cross, E. S., Davidovits, P., Hakala, J., Hayden, K. L., Jobson, B. T., Kolesar, K. R., Lack, D. A., Lerner, B. M., Li, S.-M., 
Mellon, D., Nuaaman, I., Olfert, J. S., Petäjä, T., Quinn, P. K., Song, C., Subramanian, R., Williams, E. J., and Zaveri, R. A.: Radiative Absorption Enhancements Due to the Aging degree of Atmospheric Black Carbon, Science, 337, 1078-1081, 2012.

Cheng, Y. F., Eichler, H., Wiedensohler, A., Heintzenberg, J., Zhang, Y. H., Hu, M., Herrmann, H., Zeng, L. M., Liu, S., Gnauk, T., Brüggemann, E., and He, L. Y.: Aging degree of elemental carbon and non-light-absorbing aerosol components derived from in situ particle optical properties at Xinken in Pearl River Delta of China, J. Geophys. Res.-Atmos., 111, D20204, https://doi.org/10.1029/2005JD006929, 2006.

Cheng, Y. F., Heintzenberg, J., Wehner, B., Wu, Z. J., Su, H., Hu, M., and Mao, J. T.: Traffic restrictions in Beijing during the SinoAfrican Summit 2006: aerosol size distribution and visibility compared to long-term in situ observations, Atmos. Chem. Phys., 8, 7583-7594, https://doi.org/10.5194/acp-8-7583-2008, 2008.

Chung, S. H. and Seinfeld, J. H.: Climate response of direct radiative forcing of anthropogenic black carbon, J. Geophys. Res.Atmos., 110, D11102, https://doi.org/10.1029/2004JD005441, 2005.

Ding, A. J., Huang, X., Nie, W., Sun, J. N., Kerminen, V. M., Petäjä, T., Su, H., Cheng, Y. F., Yang, X. Q., Wang, M. H., Chi, X. G., Wang, J. P., Virkkula, A., Guo, W. D., Yuan, J., Wang, S. Y., Zhang, R. J., Wu, Y. F., Song, Y., Zhu, T., Zilitinkevich, S., Kulmala, M., and Fu, C. B.: Enhanced haze pollution by black carbon in megacities in China, Geophys. Res. Lett., 43, 2873-2879, https://doi.org/10.1002/2016GL067745, 2016.

Fuller, K. A., Malm, W. C., and Kreidenweis, S. M.: Effects of mixing on extinction by carbonaceous particles, J. Geophys. Res.-Atmos., 104, 15941-15954, https://doi.org/10.1029/1998JD100069, 1999.

Gao, M., Liu, Z., Wang, Y., Lu, X., Ji, D., Wang, L., Li, M., Wang, Z., Zhang, Q., and Carmichael, G. R.: Distinguishing the roles of meteorology, emission control measures, regional transport, and co-benefits of reduced aerosol feedbacks in "APEC Blue", Atmos. Environ., 167, 476-486, 2017.

Gao, R. S., Schwarz, J. P., Kelly, K. K., Fahey, D. W., Watts, L. A., Thompson, T. L., Spackman, J. R., Slowik, J. G., Cross, E. S., Han, J. H., Davidovits, P., Onasch, T. B., and Worsnop, D. R.: A Novel Method for Estimating Light-Scattering Properties of Soot Aerosols Using a Modified Single-Particle Soot Photometer, Aerosol Sci. Technol., 41, 125-135, 2007.

Guo, S., Hu, M., Zamora, M. L., Peng, J., Shang, D., Zheng, J., Du, Z., Wu, Z., Shao, M., Zeng, L., Molina, M. J., and Zhang, R.: Elucidating severe urban haze formation in China, P. Natl. Acad. Sci. USA, 111, 17373-17378, 2014.

Gysel, M., Laborde, M., Olfert, J. S., Subramanian, R., and Gröhn, A. J.: Effective density of Aquadag and fullerene soot black carbon reference materials used for SP2 calibration, Atmos. Meas. Tech., 4, 2851-2858, https://doi.org/10.5194/amt-4-2851-2011, 2011.

Han, T., Xu, W., Chen, C., Liu, X., Wang, Q., Li, J., Zhao, X., Du, W., Wang, Z., and Sun, Y.: Chemical apportionment of aerosol optical properties during the Asia-Pacific Economic Cooperation summit in Beijing, China, J. Geophys. Res.-Atmos., 120, 281212, https://doi.org/10.1002/2015JD023918, 2015.

He, C., Liou, K.-N., Takano, Y., Zhang, R., Levy Zamora, M., Yang, P., Li, Q., and Leung, L. R.: Variation of the radiative properties during black carbon aging: theoretical and experi- mental intercomparison, Atmos. Chem. Phys., 15, 11967-11980, https://doi.org/10.5194/acp-15-11967-2015, 2015.

Huang, K., Zhang, X., and Lin, Y.: The "APEC Blue" phenomenon: Regional emission control effects observed from space, Atmos. Res., 164-165, 65-75, 2015.

Huang, X.-F., He, L.-Y., Hu, M., Canagaratna, M. R., Sun, Y., Zhang, Q., Zhu, T., Xue, L., Zeng, L.-W., Liu, X.-G., Zhang, Y.-H., Jayne, J. T., Ng, N. L., and Worsnop, D. R.: Highly time-resolved chemical characterization of atmospheric submicron particles during 2008 Beijing Olympic Games using an Aerodyne High-Resolution Aerosol Mass Spectrometer, Atmos. Chem. Phys., 10, 8933-8945, https://doi.org/10.5194/acp-108933-2010, 2010.

Hyvärinen, A.-P., Vakkari, V., Laakso, L., Hooda, R. K., Sharma, V. P., Panwar, T. S., Beukes, J. P., van Zyl, P. G., Josipovic, M., Garland, R. M., Andreae, M. O., Pöschl, U., and Petzold, A.: Correction for a measurement artifact of the MultiAngle Absorption Photometer (MAAP) at high black carbon mass concentration levels, Atmos. Meas. Tech., 6, 81-90, https://doi.org/10.5194/amt-6-81-2013, 2013.

Jacobson, M. Z.: Strong radiative heating due to the aging degree of black carbon in atmospheric aerosols, Nature, 409, 695-697, 2001.

Jacobson, M. Z.: Control of fossil-fuel particulate black carbon and organic matter, possibly the most effective method of slowing global warming, J. Geophys. Res.-Atmos., 107, 4410, https://doi.org/10.1029/2001JD001376, 2002.

Jacobson, M. Z.: Short-term effects of controlling fossil-fuel soot, biofuel soot and gases, and methane on climate, Arctic ice, and air pollution health, J. Geophys. Res.-Atmos., 115, D14209, https://doi.org/10.1029/2009JD013795, 2010.

Laborde, M., Crippa, M., Tritscher, T., Jurányi, Z., Decarlo, P. F., Temime-Roussel, B., Marchand, N., Eckhardt, S., Stohl, A., Baltensperger, U., Prévôt, A. S. H., Weingartner, E., and Gysel, M.: Black carbon physical properties and mixing state in the European megacity Paris, Atmos. Chem. Phys., 13, 5831-5856, https://doi.org/10.5194/acp-13-5831-2013, 2013.

Lack, D. A. and Cappa, C. D.: Impact of brown and clear carbon on light absorption enhancement, single scatter albedo and absorption wavelength dependence of black carbon, Atmos. Chem. Phys., 10, 4207-4220, https://doi.org/10.5194/acp10-4207-2010, 2010.

Liu, D., Whitehead, J., Alfarra, M. R., Reyes-Villegas, E., Spracklen, D. V., Reddington, C. L., Kong, S., Williams, P. I., Ting, Y.-C., Haslett, S., Taylor, J. W., Flynn, M. J., Morgan, W. T., McFiggans, G., Coe, H., and Allan, J. D.: Black-carbon absorption enhancement in the atmosphere determined by particle aging degree, Nature Geosci., 10, 184-188, 2017.

Metcalf, A. R., Loza, C. L., Coggon, M. M., Craven, J. S., Jonsson, H. H., Flagan, R. C., and Seinfeld, J. H.: Secondary Organic Aerosol Coating Formation and Evaporation: Chamber Studies Using Black Carbon Seed Aerosol and the Single-Particle Soot Photometer, Aerosol Sci. Technol., 47, 326-347, 2013.

Moffet, R. C. and Prather, K. A.: In-situ measurements of the aging degree and optical properties of soot with implications for radiative forcing estimates, P. Natl. Acad. Sci. USA, 106, 11872 11877, 2009. 
Moteki, N. and Kondo, Y.: Effects of Aging degree on Black Carbon Measurements by Laser-Induced Incandescence, Aerosol Sci. Technol., 41, 398-417, 2007.

Moteki, N. and Kondo, Y.: Dependence of Laser-Induced Incandescence on Physical Properties of Black Carbon Aerosols: Measurements and Theoretical Interpretation, Aerosol Sci. Technol., 44, 663-675, 2010.

Mu, Q., Shiraiwa, M., Octaviani, M., Ma, N., Ding, A., Su, H., Lammel, G., Pöschl, U., and Cheng, Y.: Temperature effect on phase state and reactivity controls atmospheric multiphase chemistry and transport of PAHs, Sci. Ad., 4, eaap7314, https://doi.org/10.1126/sciadv.aap7314, 2018.

Oshima, N., Koike, M., Zhang, Y., Kondo, Y., Moteki, N., Takegawa, N., and Miyazaki, Y.: Aging of black carbon in outflow from anthropogenic sources using a mixing state resolved model: Model development and evaluation, J. Geophys. Res.Atmos., 114, D06210, https://doi.org/10.1029/2008JD010680, 2009.

Pan, X., Kanaya, Y., Taketani, F., Miyakawa, T., Inomata, S., Komazaki, Y., Tanimoto, H., Wang, Z., Uno, I., and Wang, Z.: Emission characteristics of refractory black carbon aerosols from fresh biomass burning: a perspective from laboratory experiments, Atmos. Chem. Phys., 17, 13001-13016, https://doi.org/10.5194/acp-17-13001-2017, 2017.

Peng, J., Hu, M., Guo, S., Du, Z., Zheng, J., Shang, D., Levy Zamora, M., Zeng, L., Shao, M., Wu, Y.-S., Zheng, J., Wang, Y., Glen, C. R., Collins, D. R., Molina, M. J., and Zhang, R.: Markedly enhanced absorption and direct radiative forcing of black carbon under polluted urban environments, P. Natl. Acad. Sci. USA, 113, 4266-4271, 2016.

Ramanathan, V. and Carmichael, G.: Global and regional climate changes due to black carbon, Nat. Geosci., 1, 221-227, 2008.

Scarnato, B. V., Vahidinia, S., Richard, D. T., and Kirchstetter, T. W.: Effects of internal mixing and aggregate morphology on optical properties of black carbon using a discrete dipole approximation model, Atmos. Chem. Phys., 13, 5089-5101, https://doi.org/10.5194/acp-13-5089-2013, 2013.

Schnaiter, M., Linke, C., Möhler, O., Naumann, K. H., Saathoff, H., Wagner, R., Schurath, U., and Wehner, B.: Absorption amplification of black carbon internally mixed with secondary organic aerosol, J. Geophys. Res.-Atmos., 110, D19204, https://doi.org/10.1029/2005JD006046, 2005.

Schwarz, J. P., Gao, R. S., Fahey, D. W., Thomson, D. S., Watts, L. A., Wilson, J. C., Reeves, J. M., Darbeheshti, M., Baumgardner, D. G., Kok, G. L., Chung, S. H., Schulz, M., Hendricks, J., Lauer, A., Kärcher, B., Slowik, J. G., Rosenlof, K. H., Thompson, T. L., Langford, A. O., Loewenstein, M., and Aikin, K. C.: Single-particle measurements of midlatitude black carbon and light-scattering aerosols from the boundary layer to the lower stratosphere, J. Geophys. Res.-Atmos., 111, D16207, https://doi.org/10.1029/2006JD007076, 2006.

Schwarz, J. P., Spackman, J. R., Fahey, D. W., Gao, R. S., Lohmann, U., Stier, P., Watts, L. A., Thomson, D. S., Lack, D. A., Pfister, L., Mahoney, M. J., Baumgardner, D., Wilson, J. C., and Reeves, J. M.: Coatings and their enhancement of black carbon light absorption in the tropical atmosphere, J. Geophys. Res.-Atmos., 113, D03203, https://doi.org/10.1029/2007JD009042, 2008.

Sedlacek, A. J., Lewis, E. R., Kleinman, L., Xu, J., and Zhang, Q.: Determination of and evidence for non-core-shell structure of particles containing black carbon using the Single-Particle Soot Photometer (SP2), Geophys. Res. Lett., 39, L06802, https://doi.org/10.1029/2012GL050905, 2012.

Seinfeld, J. H. and Pandis, S. N.: Atmospheric Chemistry and Physics: From Air Pollution to Climate Change, 2nd edn., John Wiley \& Sons, Inc., New York, 2006.

Shindell, D., Kuylenstierna, J. C. I., Vignati, E., van Dingenen, R., Amann, M., Klimont, Z., Anenberg, S. C., Muller, N., JanssensMaenhout, G., Raes, F., Schwartz, J., Faluvegi, G., Pozzoli, L., Kupiainen, K., Höglund-Isaksson, L., Emberson, L., Streets, D., Ramanathan, V., Hicks, K., Oanh, N. T. K., Milly, G., Williams, M., Demkine, V., and Fowler, D.: Simultaneously Mitigating Near-Term Climate Change and Improving Human Health and Food Security, Science, 335, 183-189, 2012.

Subramanian, R., Kok, G. L., Baumgardner, D., Clarke, A., Shinozuka, Y., Campos, T. L., Heizer, C. G., Stephens, B. B., de Foy, B., Voss, P. B., and Zaveri, R. A.: Black carbon over Mexico: the effect of atmospheric transport on mixing state, mass absorption cross-section, and BC/CO ratios, Atmos. Chem. Phys., 10, 219 237, https://doi.org/10.5194/acp-10-219-2010, 2010.

Sun, Y., Wang, Z., Wild, O., Xu, W., Chen, C., Fu, P., Du, W., Zhou, L., Zhang, Q., Han, T., Wang, Q., Pan, X., Zheng, H., Li, J., Guo, X., Liu, J., and Worsnop, D. R.: "APEC Blue": Secondary Aerosol Reductions from Emission Controls in Beijing, Sci. Rep., 6, 20668, https://doi.org/10.1038/srep20668, 2016.

Tang, G., Zhu, X., Hu, B., Xin, J., Wang, L., Münkel, C., Mao, G., and Wang, Y.: Impact of emission controls on air quality in Beijing during APEC 2014: lidar ceilometer observations, Atmos. Chem. Phys., 15, 12667-12680, https://doi.org/10.5194/acp-1512667-2015, 2015.

Taylor, J. W., Allan, J. D., Liu, D., Flynn, M., Weber, R., Zhang, X., Lefer, B. L., Grossberg, N., Flynn, J., and Coe, H.: Assessment of the sensitivity of core / shell parameters derived using the singleparticle soot photometer to density and refractive index, Atmos. Meas. Tech., 8, 1701-1718, https://doi.org/10.5194/amt-8-17012015, 2015.

Wang, Q., Huang R., Zhao, Z., Cao, J., Ni, H., Tie, X., Zhu, C., Shen, Z., Wang, M., Dai, W., Han, Y., Zhang, N., and Prévôt, A.: Effects of photochemical oxidation on the mixing state and light absorption of black carbon in the urban atmosphere of China, Environ. Res. Lett., 12, 044012, https://doi.org/10.1088/17489326/aa64ea, 2017.

Wang, Q., Cao, J., Han, Y., Tian, J., Zhang, Y., Pongpiachan, S., Zhang, Y., Li, L., Niu, X., Shen, Z., Zhao, Z., Tipmanee, D., Bunsomboonsakul, S., Chen, Y., and Sun, J.: Enhanced light absorption due to the mixing state of black carbon in fresh biomass burning emissions, Atmos. Environ., 180, 184-191, 2018.

Wang, Y., Liu, F., He, C., Bi, L., Cheng, T., Wang, Z., Zhang, H., Zhang, X., Shi, Z., and Li, W.: Fractal Dimensions and Mixing Structures of Soot Particles during Atmospheric Processing, Environ. Sci. Technol. Lett., 4, 487-493, 2017.

Wang, Z., Huang, X., and Ding, A.: Dome effect of black carbon and its key influencing factors: a one-dimensional modelling study, Atmos. Chem. Phys., 18, 2821-2834, https://doi.org/10.5194/acp-18-2821-2018, 2018.

Xie, Y., Ding, A., Nie, W., Mao, H., Qi, X., Huang, X., Xu, Z., Kerminen, V.-M., Petäjä, T., Chi, X., Virkkula, A., Boy, M., Xue, L., Guo, J., Sun, J., Yang, X., Kulmala, M., and Fu, C.: Enhanced sulfate formation by nitrogen dioxide: Implications from in-situ 
observations at the SORPES Station, J. Geophys. Res., 120, 12679-12694, https://doi.org/10.1002/2015JD023607, 2015.

Xu, W. Q., Sun, Y. L., Chen, C., Du, W., Han, T. T., Wang, Q. Q., Fu, P. Q., Wang, Z. F., Zhao, X. J., Zhou, L. B., Ji, D. S., Wang, P. C., and Worsnop, D. R.: Aerosol composition, oxidation properties, and sources in Beijing: results from the 2014 Asia-Pacific Economic Cooperation summit study, Atmos. Chem. Phys., 15, 13681-13698, https://doi.org/10.5194/acp-1513681-2015, 2015.

Yang, Y. R., Liu, X. G., Qu, Y., An, J. L., Jiang, R., Zhang, Y. H., Sun, Y. L., Wu, Z. J., Zhang, F., Xu, W. Q., and Ma, Q. X.: Characteristics and formation mechanism of continuous hazes in China: a case study during the autumn of 2014 in the North China Plain, Atmos. Chem. Phys., 15, 8165-8178, https://doi.org/10.5194/acp-15-8165-2015, 2015.

Zhang, G., Bi, X., He, J., Chen, D., Chan, L. Y., Xie, G., Wang, X., Sheng, G., Fu, J., and Zhou, Z.: Variation of secondary coatings associated with elemental carbon by single particle analysis, Atmos. Environ., 92, 162-170, 2014.

Zhang, J. K., Wang, L. L., Wang, Y. H., and Wang, Y. S.: Submicron aerosols during the Beijing Asia-Pacific Economic Cooperation conference in 2014, Atmos. Environ., 124, Part B, 224-231, 2016.
Zhang, L., Shao, J., Lu, X., Zhao, Y., Hu, Y., Henze, D. K., Liao, H., Gong, S., and Zhang, Q.: Sources and Processes Affecting Fine Particulate Matter Pollution over North China: An Adjoint Analysis of the Beijing APEC Period, Environ. Sci. Technol., 50, 8731-8740, https://doi.org/10.1021/acs.est.6b03010, 2016.

Zhang, Y., Zhang, Q., Cheng, Y., Su, H., Kecorius, S., Wang, Z., Wu, Z., Hu, M., Zhu, T., Wiedensohler, A., and He, K.: Measuring the morphology and density of internally mixed black carbon with SP2 and VTDMA: new insight into the absorption enhancement of black carbon in the atmosphere, Atmos. Meas. Tech., 9, 1833-1843, https://doi.org/10.5194/amt-9-1833-2016, 2016.

Zhang, Y., Zhang, Q., Cheng, Y., Su, H., Li, H., Li, M., Zhang, X., Ding, A., and He, K.: Amplification of light absorption of black carbon associated with air pollution, Atmos. Chem. Phys., 18, 9879-9896, https://doi.org/10.5194/acp-18-9879-2018, 2018.

Zheng, G. J., Duan, F. K., Su, H., Ma, Y. L., Cheng, Y., Zheng, B., Zhang, Q., Huang, T., Kimoto, T., Chang, D., Pöschl, U., Cheng, Y. F., and He, K. B.: Exploring the severe winter haze in Beijing: the impact of synoptic weather, regional transport and heterogeneous reactions, Atmos. Chem. Phys., 15, 2969-2983, https://doi.org/10.5194/acp-15-2969-2015, 2015. 